\title{
Antimicrobial activity of a continuous visible light disinfection system
}

\author{
William A. Rutala, PhD, MPH ${ }^{1,2}$, Hajime Kanamori, MD, PhD, MPH ${ }^{1,2,3}$, Maria F. Gergen, MT \\ (ASCP) $^{1,2}$, Emily E. Sickbert-Bennett, PhD $^{1,2}$, Daniel J. Sexton, MD $^{4}$, Deverick J. Anderson, \\ MD, MPH ${ }^{4}$, Jeffrey Laux, PhD $^{5}$, David J. Weber, MD, MPH ${ }^{1,2}$, CDC Prevention Epicenters \\ Program \\ ${ }^{1}$ Hospital Epidemiology, University of North Carolina Hospitals, Chapel Hill, North Carolina \\ 2Division of Infectious Diseases, UNC School of Medicine, Chapel Hill, North Carolina \\ ${ }^{3}$ Infection Control and Laboratory Diagnostics, Internal Medicine, Tohoku University Graduate \\ School of Medicine, Sendai, Japan \\ ${ }^{4}$ Duke Infection Control Outreach Network, Division of Infectious Diseases, Duke University \\ Medical Center, Durham, North Carolina \\ ${ }^{5}$ North Carolina Translational and Clinical Sciences Institute, North Carolina
}

\begin{abstract}
We evaluated the ability of high-intensity visible violet light with a peak output of $405 \mathrm{~nm}$ to kill epidemiologically important pathogens. The high irradiant light significantly reduced both vegetative bacteria and spores at some time points over a 72-hour exposure period.
\end{abstract}

\begin{abstract}
Over the last decade, substantial scientific evidence suggests that the hospital environment is an important source of organisms that, when transmitted, can cause healthcare-associated infections for several reasons. ${ }^{1}$ First, the hospital environment is commonly contaminated with epidemiologically important healthcare pathogens such as methicillin-resistant Staphylococcus aureus (MRSA), vancomycin-resistant Enterococcus (VRE), multidrugresistant (MDR) Acinetobacter, and Clostridium difficile. ${ }^{1,2}$ These pathogens share the following general characteristics: (1) devices and surfaces in the patient room are frequently contaminated; (2) an ability to survive for prolonged periods of time on environmental surfaces (eg, days to months); and (3) contact with surfaces contaminated with these results in hand or glove contamination, which may be transferred to patients. Finally, room disinfection reduces contamination with these organisms. ${ }^{1-3}$ Second, standard cleaning and disinfection methods are inadequate in most, if not all, hospitals. On average, only $50 \%$ of surfaces in hospital rooms are cleaned between patients. ${ }^{4}$ As a result, patients admitted to the rooms previously occupied by patients with MDR organisms are at a 39\%-353\% increased risk of subsequent infection (a $120 \%$ increased risk on average). ${ }^{4}$
\end{abstract}

Author for correspondence: William A. Rutala, PhD, UNC School of Medicine, Division of Infectious Diseases, UNC School of Medicine, Bioinformatics Building, CB\#7030, Chapel Hill, NC 27514-7030. brutala@ med.unc.edu.

Conflicts of interest. Drs Rutala and Weber are consultants for PDI in 2017-2018 and consultants for Clorox in 2012-2016. Dr Weber is a consultant for Germitec. 
An overhead light fixture technology, which continuously and safely disinfects the environment using light-emitting diodes (LEDs) by emitting a high-intensity, narrowspectrum (HINS) light, has been proposed as an infection prevention strategy. ${ }^{5-7}$ This technology uses LEDs to create a narrow bandwidth of high-intensity visible violet light with a peak output of $405 \mathrm{~nm}$. The wavelength of the LEDs is certified by the manufacturer to be $405 \mathrm{~nm} \pm 3 \mathrm{~nm}$. This light in turn reacts with porphyrin molecules to generate reactive oxygen species that kill microorganisms. ${ }^{5}$ The purpose of this evaluation was to determine the effectiveness of HINS light for the reduction of epidemiologically important pathogens in the environment.

\section{Methods}

\section{Light source and irradiance}

An overhead, visible light disinfection technology (Indigo-Clean, Kenall Manufacturing, Kenosha, WI) was evaluated in 2 different clinical configurations. In phase 1 ("white" lights), two $61-\mathrm{cm} \times 61$-cm (2-foot $\times 2$-foot) blended-white, ceiling-mounted fixtures were used to provide both disinfection and ambient white illumination for use in normal clinical conditions in an occupied room. The measured surface irradiance of this "white" disinfecting light at the pathogen location was $\sim 0.12-0.16 \mathrm{~mW} / \mathrm{cm}^{2}$. In phase 2 ("blue" light), a higher-level of disinfection light was studied by adding a $61-\mathrm{cm} \times 122-\mathrm{cm}$ (2-foot $\times$ 4 -foot) overhead "blue" light fixture to the 2 preexisting $61-\mathrm{cm} \times 61-\mathrm{cm}$ overhead, blendedwhite fixtures. The measured surface irradiance of disinfecting "blue" light at the pathogen location was $\sim 0.34-0.44 \mathrm{~mW} / \mathrm{cm}^{2}$. The surface irradiance measurements in the control area yielded values of $0.00 \mathrm{~mW} / \mathrm{cm}^{2}$ (no measurable disinfecting light). These surface irradiance measurements were made using a National Institute of Standards and Technology (NIST)calibrated spectroradiometer (model no. USB2000 +, Ocean Optics, Wesley Chapel, FL).

Phase 1 and phase 2 testing were conducted in a $12.5 \mathrm{~m}^{2}\left(134 \mathrm{ft}^{2}\right)$ room. The room used did not have windows or external sources of light. Each of the 3 lights described above were connected via separate light switches and were simply switched "on" and "off" at the wall switch. Light placement was designed to treat the study room with intensity sufficient to cause inactivation of test bacteria. In both phases, the indicated lights were operated continuously (ie, 24 hours per day, 7 days per week) during the sampling period, and no other lights were present in the study room.

\section{Study design}

The vegetative bacteria were grown on sheep blood agar. Serial dilutions of inocula were made with trypticase soy broth (TSB, Remel, Lenexa, KS). The C. difficile spore preparation was stored in Dulbecco's modified Eagle's medium (HyClone, Logan, UT), and serial dilutions were similarly made using TSB. The 4 test organisms were C. difficile spores (BI strain), a MRSA strain (ATCC 43300), a VRE strain (ATCC strain 51299), and a clinical isolate of MDR Acinetobacter baumannii. Rodac plate templates were drawn on the Formica sheet and inoculated with $10-15 \mu \mathrm{L}$ of a $10^{4}$ dilution of test organisms suspended in TSB, producing an estimated inoculum of 100-500 test organisms. After inoculation, each surface was allowed to air dry for 10 minutes after inoculation. Once dry, the test Formica sheets 
were exposed to the disinfecting light and triplicate samples were collected with Rodac plates containing Dey-Engley Neutralizing Agar after 0, 1, 3, 5, 6, 7, 24, 48, and 72 hours. These plates were then incubated based on the test organism being studied (aerobically at $37^{\circ} \mathrm{C}$ for 48 hours for bacteria and anaerobically at $37^{\circ} \mathrm{C}$ for 48 hours for C. difficile) in an AnaeroPack anaerobic gas generator (Anaeropack, Mitsubishi Gas Chemical, Tokyo, Japan). After incubation, the colony-forming units (CFU) of the test organisms on each plate were quantified. Each template area was sampled only once. Surfaces were maintained at ambient room temperature and relative humidity. A control Formica sheet was placed in an adjacent area but not exposed to the HINS light to accommodate the expected natural in vitro die-off of vegetative bacteria. Triplicate samples were collected with Rodacs at the same test times as the test surfaces. Two experimental runs were conducted for all time points.

\section{Statistical methods}

We fit a mixed-effects negative binomial model to the data using the R statistical software ${ }^{8}$ and the lme4 package. ${ }^{9}$ We modeled the "blue" light as augmenting the "white" light. Both linear and squared time variables were included in the model to account for any nonlinear effects. The full model began with a 3-way interaction of treatment $\times$ bacteria $\times$ time, and hypotheses were tested using likelihood ratio tests of progressively nested models. A $P$ value $<.05$ was considered significant.

\section{Results}

A 3-way interaction was significant $\left(\chi^{2}=265.5 ; \mathrm{df}=12 ; P<.001\right)$, indicating that the effect of the type of light treatment differed with different combinations of test organisms and time. The treatment (ie, both blue and white light) had significantly different rates of pathogen killing over time for all 4 organisms: Acinetobacter $\left(\chi^{2}=117.2 ; \mathrm{df}=4 ; P<.001\right)$, MRSA $\left(\chi^{2}=80.5 ; \mathrm{df}=4 ; P<.001\right)$, VRE $\left(\chi^{2}=150.4 ; \mathrm{df}=4 ; P<.001\right)$, and C. difficile $\left(\chi^{2}=25.8 ; \mathrm{df}=4 ; P<.001\right)$.

We also performed individual tests of the interactions between the white (vs the control) and time, and blue (vs white) and time. Both types of light treatments were associated with more rapid decreases in observed bacterial counts over time with all 4 organisms with 1 exception, the use of white light had no effect on C. difficile compared to control (Fig. 1). Specifically, the number of CFUs on test Rodac plates decreased over time for Acinetobacter with the white light $\left(\chi^{2}=95.7 ; \mathrm{df}=2 ; P<.001\right)$ and the blue light $\left(\chi^{2}=16.6 ; \mathrm{df}=2 ; P<.001\right)$; for MRSA, for both white $\left(\chi^{2}=31.7 ; \mathrm{df}=2 ; P<.001\right)$ and blue $\left(\chi^{2}=29.9 ; \mathrm{df}=2 ; P<.001\right)$; and for VRE, for both white $\left(\chi^{2}=7.1 ; \mathrm{df}=2 ; P<.029\right)$ and blue $\left(\chi^{2}=138.5 ; \mathrm{df}=2 ; P<\right.$. 001). However, white was not superior to control for C. difficile $\left(\chi^{2}=2.6 ; \mathrm{df}=2 ; P=.20\right)$, but the use of blue light increased killing of C. difficile $\left(\chi^{2}=23.9 ; \mathrm{df}=2 ; P<.001\right)$.

Table 1 lists the earliest hour by which our statistical model predicted a sustained reduction in the number of CFUs by a given percentage. Overall, the model demonstrates enhanced inactivation of pathogens with the "blue" and "white" light. 


\section{Discussion}

The use of light disinfection technology for continuous disinfection of the healthcare environment has been proposed by various investigators. ${ }^{5-7}$ The use of disinfecting lights, if effective, could augment the episodic disinfection (eg, daily) that occurs in patient rooms or care areas by preventing or reducing the microbial regrowth on surfaces following disinfection, and by reducing the microbial level due to recontamination. These light sources are thought to be safe for surfaces and for humans, ${ }^{7}$ although there has been limited human experience.

We demonstrated that the "blue" and "white" light significantly reduced the 3 vegetative test bacteria; and "blue" light yielded lower counts of C. difficile spores after 72 hours. Whether the level of these reductions are sufficient to reduce healthcare-associated infections remains uncertain, and the question requires further study.

This study was a preliminary evaluation. Future studies will need to consider costeffectiveness, multiple types of surfaces (eg, porous vs nonporous surfaces, stainless steel) with taxonomically diverse pathogens (eg, norovirus, Enterobacteriaceae) to include spores, use areas (eg, operating room), and the ability of the technology to continuously reduce the overall bioburden in inpatient and outpatient care areas and reduce HAIs. A separate issue is the acceptance of continuous light (ie, 24 hours) by patients and staff. If shorter durations of continuous light exposure are deemed necessary, the level of decontamination achieved by use during times when the patient is awake (eg, $\sim 16$ hours per day) needs further study. In addition, future studies should include rechallenging the surfaces with additional contamination (eg, every 4-6 hours). Given that environmental surfaces in a patient's room are often not thoroughly disinfected and that recontamination occurs rapidly, it is important to develop either methods of continuous disinfection or a germicide with persistant antimicrobial effectiveness.

\section{Acknowledgments.}

Kenall Manufacturing loaned UNC Hospitals the high-intensity, narrow spectrum light fixtures for the study period. They also allowed UNC Hospitals to use the NIST calibrated spectroradiometer to measure surface irradiance. Kenall had no role in the design, conduct, analysis, or publication of this study.

Financial support. No financial support was provided relevant to this article.

Dr Rutala has received an honorarium from Kenall.

\section{References}

1. Weber DJ, Rutala WA, Anderson DJ, Chen LF, Sickbert-Bennett EE, Boyce JM. Effectiveness of UV devices and hydrogen peroxide systems for terminal room decontamination: focus on clinical trials. Am J Infect Control 2016;44:e77-e84. [PubMed: 27131140]

2. Rutala WA, Weber DJ. Monitoring and improving the effectiveness of surface cleaning and disinfection. Am J Infect Control 2016;44: e69-e76. [PubMed: 27131138]

3. Stiefel U, Cadnum JL, Eckstein BC, Guerrero DM, Tima MA, Donskey CJ. Contamination of hands with methicillin-resistant Staphylococcus aureus after contact with environmental surfaces and after contact with the skin of colonized patients. Infect Control Hosp Epidemiol 2011;32:185-187.

[PubMed: 21460476] 
4. Carling P Methods for assessing the adequacy of practice and improving room disinfection. Am J Infect Control 2013;41:S20-S25. [PubMed: 23622743]

5. Maclean M, Macgregor SJ, Anderson JG, et al. Environmental decontamination of a hospital isolation room using high-intensity narrow-spectrum light. J Hosp Infect 2010;76:247-251. [PubMed: 20864210]

6. Maclean M, McKenzie K, Anderson JG, Gettinby G, MacGregor SJ. 405 nm light technology for the inactivation of pathogens and its potential role for environmental disinfection and infection control. J Hosp Infect 2014;88:1-11. [PubMed: 25066049]

7. Bache SE, Maclean M, MacGregor SJ, Anderson JG, Gettinby G, Coia JE, Taggart I. Clinical studies of the high-intensity narrow-spectrum light environmental decontamination system (HINSlight EDS) for continuous disinfection in the burn unit inpatient and outpatient settings. Burns 2012;38:69-76. [PubMed: 22103991]

8. R Foundation for Statistical Computing. R: a language and environment for statistical computing. R Core Team website https://www.R-project.org/ Published 2016 Accessed July 17, 2018.

9. Bates D, Maechler M, Bolker B, Walker S. Fitting linear mixed-effects models using lme4. J Statist Softw 2015;67:1-48.

10. Weber DJ, Rutala WA. Self-disinfecting surfaces: review of current methodologies and future prospects. Am J Infect Control 2013;41:S31-S35. [PubMed: 23622745] 


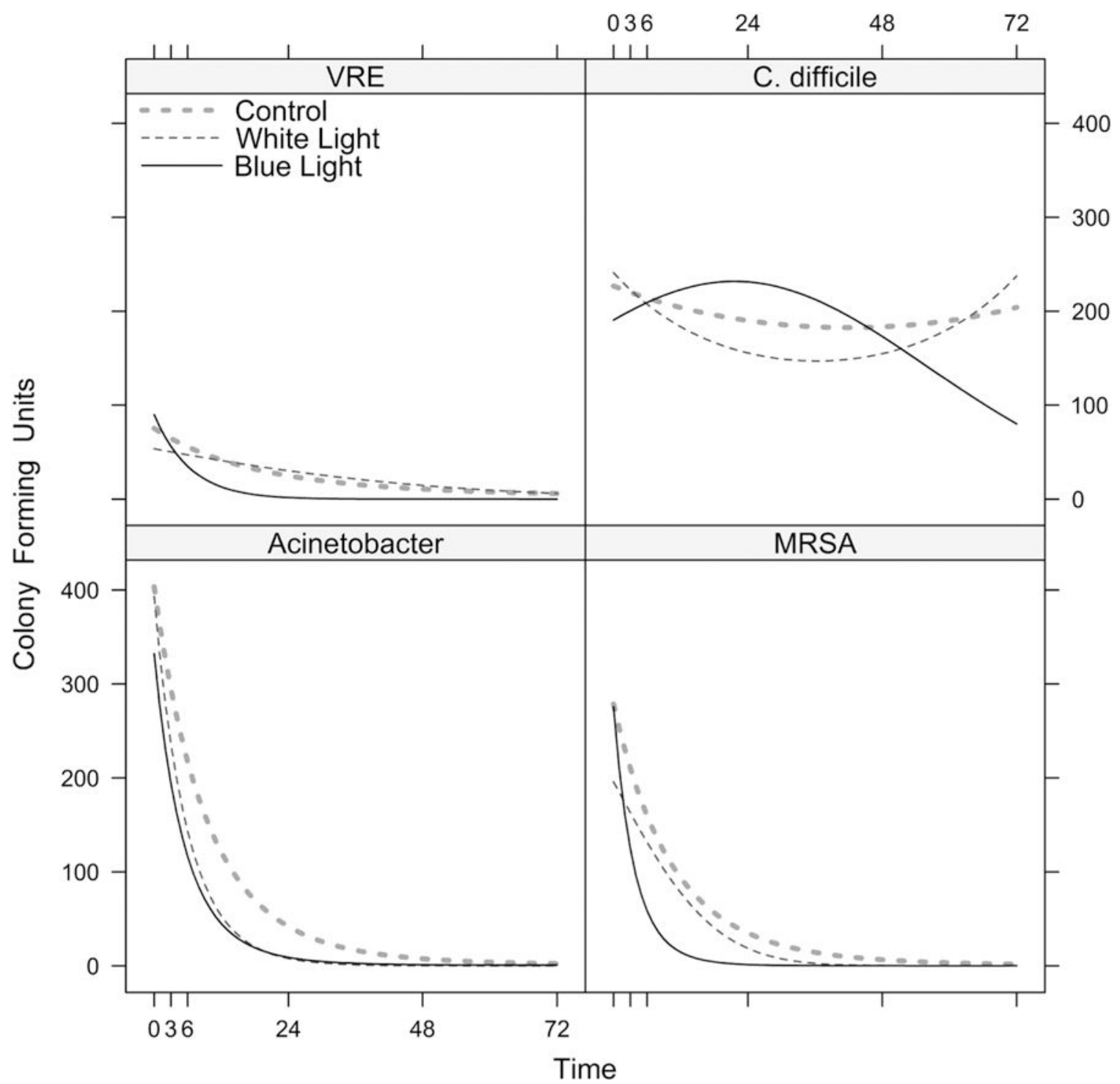

Fig. 1.

Use of a continuous visible light disinfection system and predicted reduction $(\mathrm{CFU} / \mathrm{mL})$ in epidemiological important pathogens over time. Under the "blue," "white," and control lights, the models predicted the number of colony-forming units of (A) vancomycin-resistant Enterococcus-VRE, (B) C. difficile, (C) MDR-Acinetobacter, and (D) methicillin-resistant S. aureus-MRSA (see Methods). The curves are drawn continuously over the temporal interval from 0 to 72 hours. However, in the experiment, the actual time points when the CFUs were counted were at $0,1,3,5,6,7,24,48$, and 72 hours. Because the model treats time as continuous, we were able to calculate predicted values for any time point between 0 and 72 . 


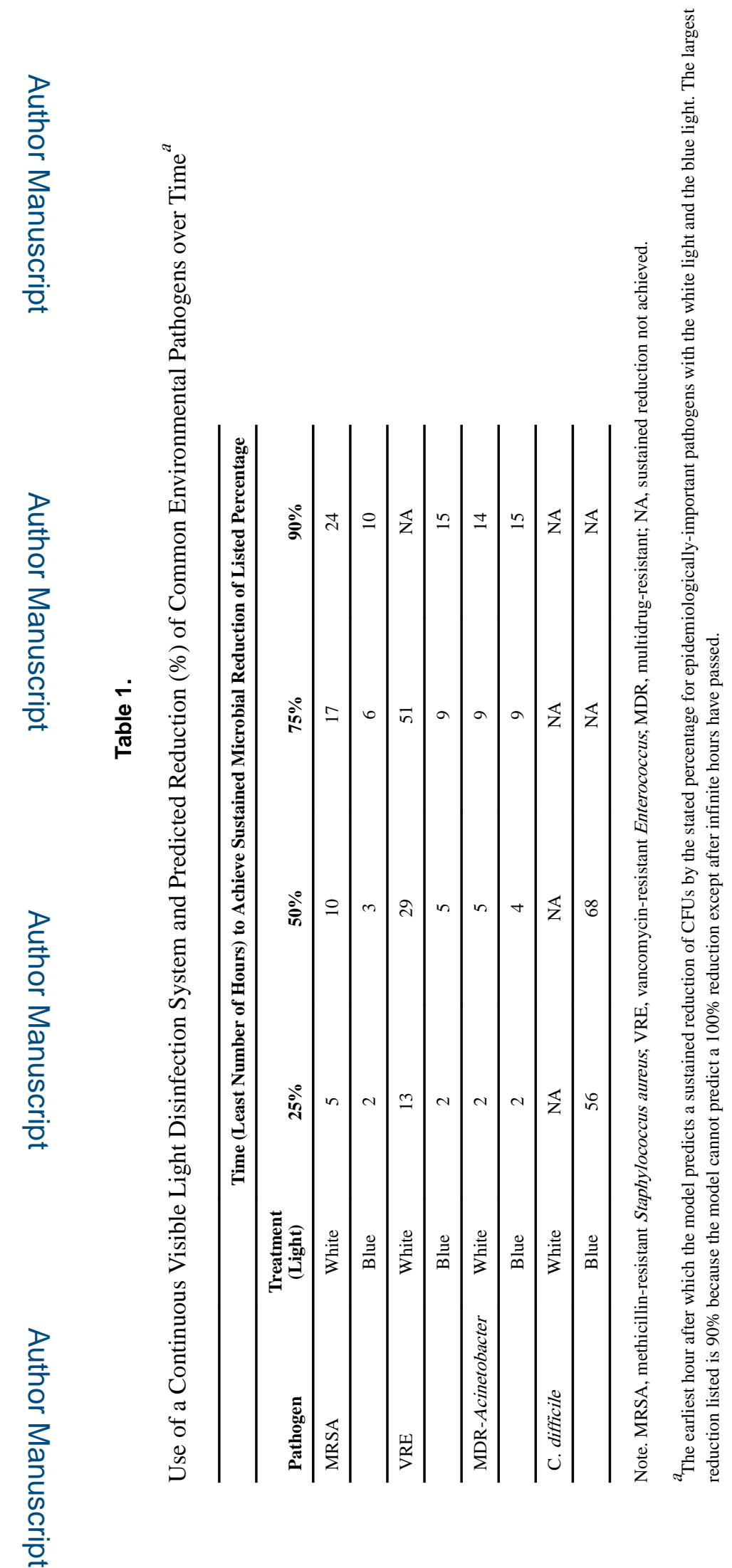

Infect Control Hosp Epidemiol. Author manuscript; available in PMC 2019 October 01. 